\title{
Experimental Analysis of Sediment Deposition Due to the Effect of an Upstream Reservoir Backwater
}

\author{
Issa E. Issa ${ }^{1,2}$, Nadhir Al-Ansari ${ }^{1}$, Moayad Khaleel ${ }^{2}$ and Sven Knutsson ${ }^{1}$ \\ 1. Department of Civil, Environmental and Natural Resources Engineering, Luleå University of Technology, Luleå 97187, Sweden \\ 2. Department of Dams and Water Resources Engineering, University of Mosul, Mosul 41002, Iraq
}

\begin{abstract}
The phenomenon of aggradation due to sediment accumulation upstream reservoirs had been studied in this research. For this purpose, groups of experiments were conducted in a laboratory with $25 \mathrm{~m}$ long, $0.80 \mathrm{~m}$ wide and $0.70 \mathrm{~m}$ deep channel. A block was built at the end of the channel to work as a dam to impound water. The channel was supplied with drainage pipes on both sides to release water out in a manner similar to what happens in reservoirs. The bed of the channel was filled with sand of 0.80 mm median sieve diameter and 0.72 geometric standard deviation. The slope was 0.0093 for all experiments. Two sizes of sand were used representing the sediment. The median diameter and geometric standard deviation of the first were $0.365 \mathrm{~mm}$ and $0.46 \mathrm{~mm}$, respectively. The second sample had $0.65 \mathrm{~mm}$ median diameter and 0.67 standard deviation. A total of 70 experiments were conducted in two groups to examine effects of sediment transport rate, particle size of sediment and flow velocity on aggradation characteristics. The results showed that there was a strong linear direct relationship between aggradation elements (length and depth) with the rate of sediment transport. Groups of dimensionless parameters affecting the aggradation characteristics were used to develop empirical equations to predict the length, maximum depth of aggradation and predict transient bed profile. The results of empirical approach were compared with the measurement data and previous numerical method. The results indicated that the percentage error was $19 \%$ to $31 \%$ for length of aggradation and $-21 \%$ to $26 \%$ for maximum depth of aggradation. The results also showed that the sediment materials were deposited closer to the body of the dam when the released water from the dam is higher than the inflow.
\end{abstract}

Key words: Aggradation, alluvial channel, reservoir sedimentation, sediment deposition.

\section{Introduction}

Aggradation phenomenon may occur due to disturbance of the equilibrium conditions of a stream when the incoming sediment is exceeding its transport capacity. Generally, aggradation in stream occurs for many reasons especially upstream large reservoirs. The impounding of water after the construction of dams causes changes in the previously existing equilibrium states-leading sediment to be deposited upstream their reservoirs and the formation of delta due to the back water flow effects. Furthermore, formation of the delta at the mouth of the reservoir may be the causes of aggradation of sediment deposited upstream [1-3]. The phenomenon due to the back water flow causes

Corresponding author: Nadhir Al-Ansari, professor, research fields: water resources and environmental engineering. E-mail: nadhir.alansari@ltu.se. elevated bed level of the stream and subsequently increases the flood level that affects directly the structures at that area [2]. Most done research focused on determining the elements of aggradation which are maximum depth of sediment deposited, length of aggradation and transient bed profile. Analytical and experimental approaches had been adopted to predict these elements due to aggradation occurrence. The experimental work under mobile bed condition is very limited compared to the analytical or mathematical approach [4-8]. Grade and Raju [2] mentioned that Sugioin (1962) was the first one to study the aggradation in laboratory flume and analyzed the data using dimensional analysis method. Soni et al. [4], Soni [5] and Jain [9] studied the aggradation in streams due to the increase of sediment at a section which was in equilibrium conditions using different sizes of 
sediment. Soni [5] conducted experiments in laboratory flume with movable bed by using recirculating system to determine aggradation characteristics due to sediment overloading for wide range. Most of previous studies conducted experiment in the laboratory under idealized conditions of a prismatic channel carrying a constant discharge and sediment load. Analytical or mathematical solutions for simulating transient bed profile were also suggested by Tayfur and Singh [7, 8], Soni [10, 11], Ribberink and Vandersand [12], Parker et al. [13] and Wu et al. [14].

The experimental works on the aggradation phenomenon upstream reservoirs are very limited and, for this reason, this study had been conducted. In this investigation, a series of experiments were carried out on a concrete channel with movable bed to study the aggradation or sediment deposited upstream in a reservoir using different water discharges, different particle sizes of sediment, varying sediment quantities and water levels in the reservoir. The experiments were divided into two groups. The first group of 50 experiments was to examine the effect of the quantity and particle size variations of the sediment on aggradation characteristics. The second group of 20 experiments was to study the flow velocity effect or reservoir operation mode on these characteristics. The data of these experiments were used to develop an empirical method to predict elements of aggradation depending on the dimensional analysis parameters. Grade and Raju [2] noted that Swamee in 1974 tested the method against measured data and compared with the numerical method.

\section{Methodology and Experimental Investigation}

Sediment transport upstream of a reservoir is affected by various factors such as varied flow hydraulics, sediment supply and reservoir characteristics. Furthermore, these factors vary from stage to stage. Therefore, it is difficult to represent the natural conditions in a laboratory setup. However, certain assumptions were considered in the experiments that can reflect the natural conditions. These assumptions are:

- Properties of bed material do not change with the operation;

- The stream is in an equilibrium condition before the construction of the dam;

- Cross sections and bed slope are constant for all the experiments;

- Resistance coefficient or bed roughness is constant for all the experiments;

- Channel reach is considered straight;

- Constant time for all experiments.

\subsection{Laboratory Details (Description of the Laboratory} Flume)

The experiments were carried out on the concrete flume in the hydraulic laboratory at Mosul University, Iraq. It is a recirculating system of rectangular cross section of $25 \mathrm{~m}$ long, $0.80 \mathrm{~m}$ wide and $0.70 \mathrm{~m}$ deep (Fig. 1). The water discharge was supplied by a pump with maximum discharge $100 \mathrm{~L} / \mathrm{s}$ which takes the water from earth tank. A concrete barrier $0.5 \mathrm{~m}$ height was constructed at the end of channel to represent the dam for impounding water. A system of two perforated pipes ( $7.5 \mathrm{~cm}$ in diameter and $9 \mathrm{~m}$ long) was installed on the sides along the end of channel that were used for releasing water from reservoir to represent the flow in it. The water discharge was controlled by sluice gate installed at upstream of the channel and measured using calibrated rectangular weir down-stream the system (end of releasing basin) (Fig. 1). The water level in the channel was controlled by adjustable valves at the end of two pipes (at concrete barrier). Flow turbulence was damped by strainer that was set up at the entrance of the channel after sluice gate. The channel bed was covered with sand (median sieve diameter $d_{50}=0.80 \mathrm{~mm}$, specific gravity $G_{s}=2.65$ and graphical standard deviation $\sigma=0.72$ ) of average depth of $15 \mathrm{~cm}$ thick and leveled to bed slope of 0.0093 


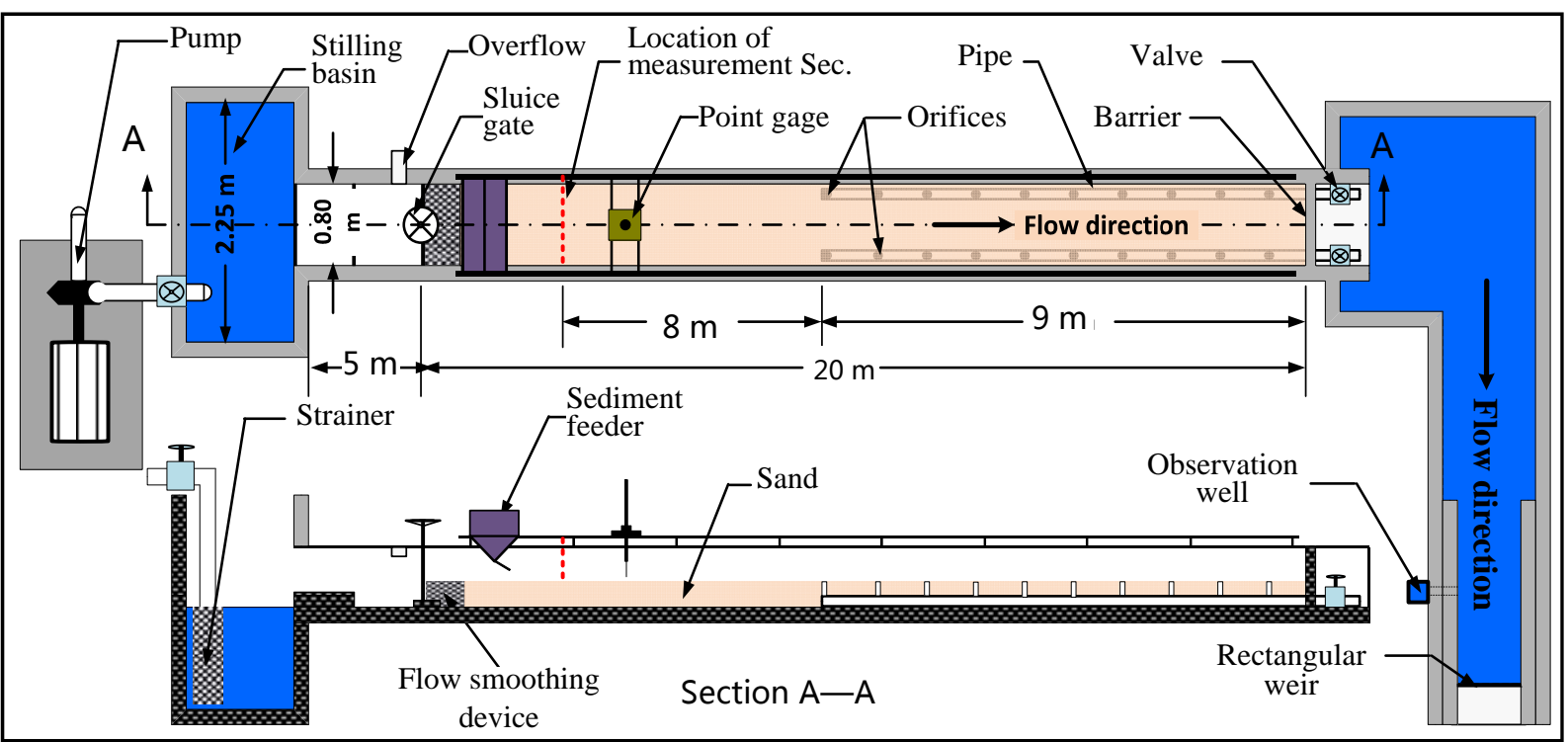

Fig. 1 Schematic view of the experiment system (all dimensions in $\mathbf{m}$ ).

for all experiments. A pointer gage having minimum count rate of $0.01 \mathrm{~cm}$ was installed on the movable carriage which was used to measure the water levels and bed elevations.

The required sediment was supplied via a vibrating sediment feeder at $2 \mathrm{~m}$ upstream the measurement section which was distributing the sediment over the width of the channel.

\subsection{Experimental Procedure and Program}

Two groups of experiments were conducted in this study. In the first group, five different water discharges with five different sediment quantities were used to study their effect on the aggradation characteristics. For each water discharge and sediment amount, two particle sizes of sediment were used to get an idea about the effect of sediment particle size on the aggradation characteristics. The two sediment particle sizes ( $\mathrm{A}$ and $\mathrm{B}$ ) were injected having $d_{50}=0.365$ and $0.65 \mathrm{~mm}$ and graphical standard deviation $\sigma=0.67$ and 0.46 , respectively. In total, 50 runs were conducted in this part which are summarized in Table 1 (Group I).

To study effect of reservoir operation on the aggradation characteristic, another group of experiments was conducted using one water discharge and constant sediment amount with 10 different water levels at the reservoir for each sediment type. For this case, 20 runs were performed (Table 1, Group II).

As it was mentioned earlier, the experiments were performed on mobile bed. The channel was given the initial bed elevations and the re-circulatory channel system was quietly filled with water from an external source. Then water level in the channel was adjusted to required level to avoid disturbing the bed form of the channel. The pump was turned on and the valve was slowly adjusted to allow attained the required discharge. Dry sediment was injected during the test at the section upstream the channel with constant rate using sediment sand feeder. During the aggradation test, the water surface levels were recorded at time $0,30,60$ $\mathrm{min}$ and at $0.5 \mathrm{~m}$ intervals along the channel. After 60 min, the run was stopped and the bed elevations were measured at section of $0.5 \mathrm{~m}$ interval along the channel. At each individual section, three points across the width of the channel were measured. Furthermore, the length and maximum depth of aggradation were measured after each run. The added sediment was removed from the channel after each run and was put in its former position along the channel before each run. The above process was repeated for each experiment. The total number of experiments conducted was 70 and the results are tabulated in Table 1. 
Table 1 Results of the conducted experiments in Groups I and II.

\begin{tabular}{|c|c|c|c|c|c|c|c|c|c|c|c|c|c|}
\hline \multirow{3}{*}{ Group I } & & & \multicolumn{11}{|c|}{ Water discharge $Q \times 10^{-3}\left(\mathrm{~m}^{3} / \mathrm{s}\right)$} \\
\hline & & & \multicolumn{3}{|c|}{8.75} & \multicolumn{2}{|c|}{11.65} & \multicolumn{2}{|c|}{14.41} & \multicolumn{2}{|c|}{20.94} & \multicolumn{2}{|c|}{23.3} \\
\hline & & & $l(\mathrm{~m})$ & $Z_{i}(\mathrm{cr}$ & & $l(\mathrm{~m})$ & $\overline{Z_{i}(\mathrm{~cm})}$ & $l(\mathrm{~m})$ & $\overline{Z_{i}(\mathrm{~cm})}$ & $l(\mathrm{~m})$ & $Z_{i}(\mathrm{~cm})$ & $l(\mathrm{~m})$ & $Z_{i}(\mathrm{~cm})$ \\
\hline \multirow{10}{*}{ 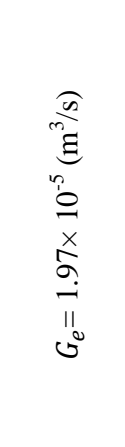 } & \multirow{2}{*}{0.91} & A & 5.70 & 1.20 & & 7.65 & 2.07 & 5.1 & 2.63 & 6.85 & 2.03 & 5.70 & 2.67 \\
\hline & & $\mathrm{B}$ & 5.65 & 0.83 & & 7.6 & 1.50 & 5.09 & 1.87 & 6.72 & 1.4 & 5.66 & 1.87 \\
\hline & \multirow{2}{*}{1.21} & A & 5.73 & 1.43 & & 7.69 & 2.23 & 5.13 & 2.97 & 6.88 & 2.33 & 5.76 & 2.77 \\
\hline & & B & 5.67 & 1.07 & & 7.65 & 1.70 & 5.12 & 2.17 & 6.77 & 1.73 & 5.7 & 2.00 \\
\hline & \multirow{2}{*}{1.5} & A & 5.80 & 1.70 & & 8.00 & 2.43 & 5.18 & 3.03 & 7.07 & 2.53 & 5.86 & 3.00 \\
\hline & & B & 5.72 & 1.37 & & 7.75 & 1.93 & 5.15 & 2.36 & 6.8 & 2.03 & 5.76 & 2.47 \\
\hline & \multirow{2}{*}{1.82} & A & 5.82 & 1.97 & & 8.13 & 2.93 & 5.25 & 3.17 & 7.21 & 2.73 & 5.95 & 3.40 \\
\hline & & B & 5.76 & 1.60 & & 7.90 & 2.37 & 5.18 & 2.53 & 6.84 & 2.23 & 5.95 & 2.80 \\
\hline & \multirow{2}{*}{1.97} & A & 5.86 & 2.43 & & 8.17 & 3.17 & 5.37 & 3.20 & 7.35 & 2.90 & 6.0 & 3.56 \\
\hline & & B & 5.79 & 1.97 & & 8.10 & 2.53 & 5.25 & 2.67 & 6.95 & 2.37 & 5.96 & 2.97 \\
\hline \multirow{2}{*}{\multicolumn{4}{|c|}{$\begin{array}{l}\text { Group II } \\
Q=23.3 \times 10^{-3}\left(\mathrm{~m}^{3} / \mathrm{s}\right)\end{array}$}} & \multicolumn{10}{|c|}{ Initial average water flow velocity $u(\mathrm{~m} / \mathrm{s})$} \\
\hline & & & & 0.33 & 0.35 & 0.48 & 0.564 & 0.625 & 0.685 & 0.72 & 0.74 & 0.87 & 0.96 \\
\hline \multirow{4}{*}{ 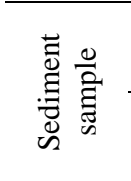 } & \multirow{2}{*}{ A } & \multicolumn{2}{|c|}{$l(\mathrm{~m})$} & 2.55 & 2.7 & 4.0 & 5.76 & 5.86 & 6.95 & 8.12 & 8.48 & 9.65 & 10.6 \\
\hline & & \multicolumn{2}{|c|}{$Z_{i}(\mathrm{~cm})$} & 4.93 & 4.7 & 3.53 & 3.1 & 3.0 & 2.65 & 2.33 & 2.3 & 2.13 & 2.04 \\
\hline & $\mathrm{P}$ & \multicolumn{2}{|c|}{$l(\mathrm{~m})$} & 2.5 & 2.67 & 3.85 & 5.6 & 5.7 & 6.86 & 8.0 & 8.37 & 9.4 & 10.45 \\
\hline & D & \multicolumn{2}{|c|}{$Z_{i}(\mathrm{~cm})$} & 4.5 & 4.2 & 3.23 & 2.73 & 2.6 & 2.57 & 2.47 & 2.3 & 2.3 & 2.15 \\
\hline
\end{tabular}

$l=$ length of aggradation; $G_{e}=$ quantity of sediment; $Q=$ water discharge; $Z_{i}=$ maximum depth of aggradation; $u=$ average flow velocity; A and B represent for sediment samples.

\section{Analysis and Discussion of Results}

Elements of aggradation or sediment deposition characteristics are affected by several factors such as flow characteristics, quantity and properties of sediment transport, stream and reservoir geometry and operation mode of the reservoir. These elements can be expressed by dimensionless parameters using Buckingham pi-theorem method that is used to derive dimensionless relationship as follows:

(1) Length of transient bed profile

$$
l=f\left(G_{e}, u, t, R_{b}, g, S_{i}, d_{50}, \sigma\right)
$$

where, $t=$ test time; $R_{b}=$ hydraulic radius; $g=$ acceleration due to gravity; $d_{50}=$ median sieve diameter; $S_{i}=$ slope of energy line and $\sigma=$ geometric standard deviation.

For very small energy slopes, its effect can be neglected. Therefore, Eq. (1) becomes:

$$
l=f\left(G_{e}, u, t, R_{b}, g, d_{50}, \sigma\right) .
$$

Using Buckingham pi-theorem, Eq. (2) can be written as:

$$
\frac{l}{R_{b}}=f\left[\frac{G_{e} \cdot t}{R_{b}{ }^{3}}, \frac{u \cdot t}{R_{b}}, F r, \frac{d_{50}}{R_{b}}, \sigma\right] .
$$

(2) Aggradation depth

The maximum depth of aggradation has been expressed by Soni [5] as:

$$
Z_{i}=\frac{G_{e} \cdot t}{(1-p) A_{i} \cdot l}
$$

where, $A_{i}=$ shape factor of transient bed profile and $p=$ porosity of sediment.

The depth of aggradation $(Z)$ at any point $(X)$ along the transient bed can be expressed by:

$$
Z=f\left(X, l, Z_{i}, t, u, G_{e}, R_{b}\right) .
$$

Using Buckingham pi-theorem, Eq. (5) can be written as:

$$
\frac{Z}{Z_{i}}=f\left[\frac{X}{l}, \frac{u \cdot t}{R_{b}}, \frac{Z_{i}}{R_{b}}, \frac{l}{R_{b}}, \frac{G_{e} \cdot t}{R_{b}{ }^{3}}\right] .
$$

The experimental measurements in this investigation were used to study the factors that are affecting these elements as follows.

\subsection{Amount and Properties of Sediment}

Five different quantities of sediment for each particle size A and B were used to study its effects on the length and depth of aggradation (Group I). The 
results showed that aggradation length increases directly with increasing sediment quantity (Fig. 2). This also applies to the maximum depth of aggradation that always lies at the end of the transient bed towards the downstream limit (Fig. 3). On the contrary, the length and depth of aggradation decrease with increasing sediment particle size for the same flow conditions. When the particle size of the sediments was changed from A to B (increase about 78\%), then the reduction for the length and depth of aggradation reached $5.4 \%$ and $31 \%$, respectively. This is believed to be due to the fact that relatively large particles are deposited first away from the dam while fine particles are deposited closer toward the dam $[15,16]$.

\subsection{Reservoir Operation Mode}

The effect of flow characteristics was studied through 20 experiments which were conducted using 10 different cases of flow (reservoir water stage) for one water discharge and sediment transport rate for each sediment type (A and B, Group II). The results indicated that the length of aggradation increases directly with increasing flow velocity or decreasing water stage in the reservoir for the same conditions of water discharge and sediment quantity.

This is in contrast to aggradation depth which decreases with increasing flow velocity (Fig. 4). These results are believed to be due to the decrease of the backwater flow effect. Therefore, increasing of the out flow from the reservoir (release of water through the dam) without any increase of the inflow from the River Tigris causes an increase in sediment transport rate entering the reservoir. This fact confirms the findings of Lai and Shen [17], Shen [18] and Issa et al. [19]. The relationships between length and depth of aggradation and flow condition require more experiments due to the number of factors involved. The length of aggradation is defined by the variables listed in Eq. (1) while the depth of aggradation depends on the variables listed in Eq. (6).
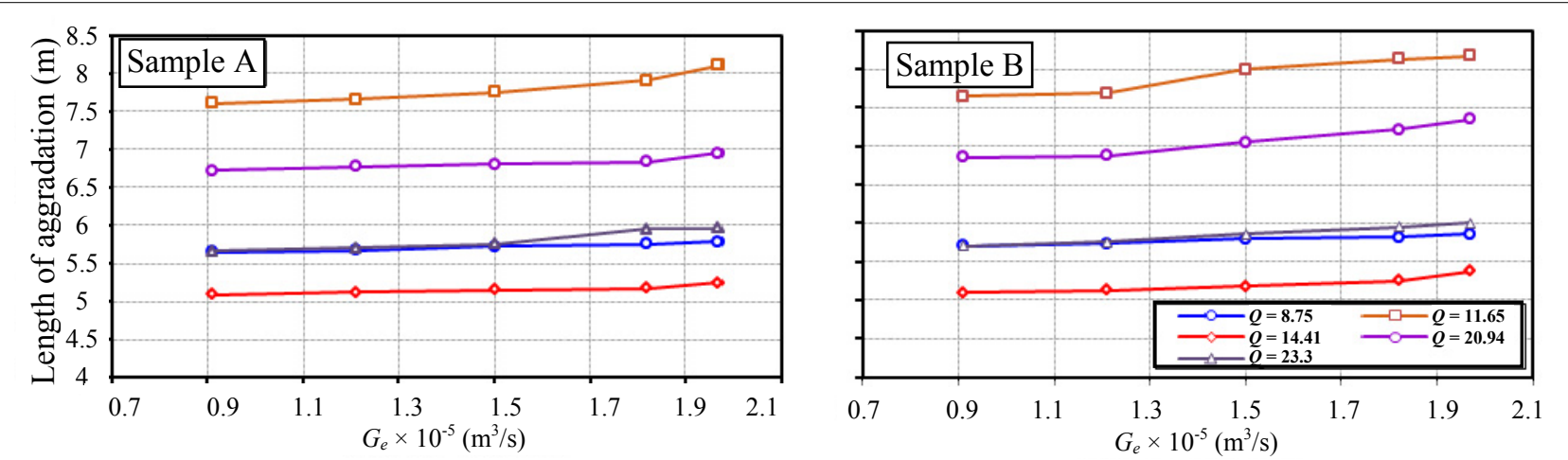

Fig. 2 Variation of length of aggradation $(l)$ with quantity of sediment $\left(G_{e}\right)$ for experiments of Group I.
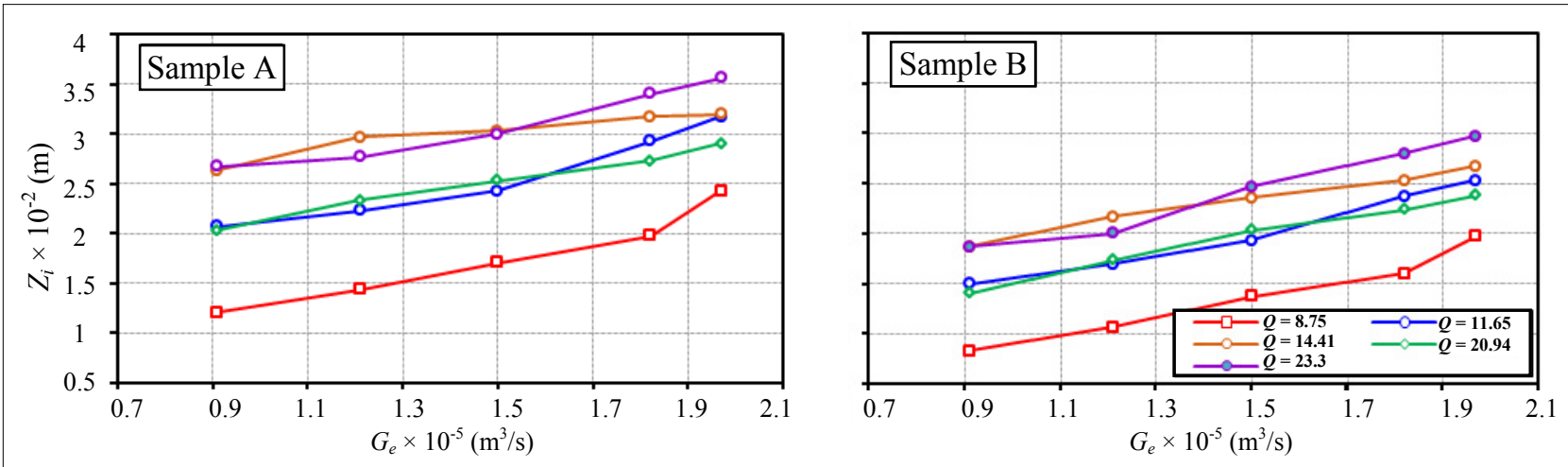

Fig. 3 Variation of maximum depth of aggradation $\left(Z_{i}\right)$ with quantity of sediment $\left(G_{e}\right)$ for experiments of Group I. 


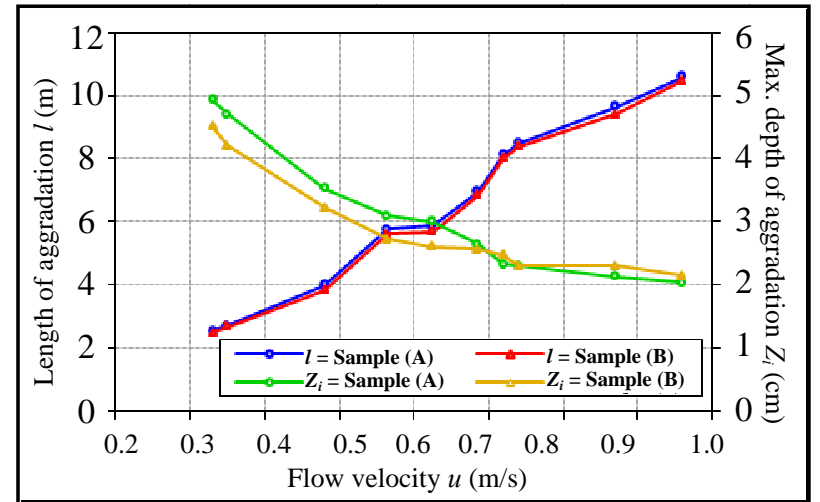

Fig. 4 Variation of length $(l)$ and maximum depth of aggradation $\left(Z_{i}\right)$ with flow velocity $(u)$ for experiments Group II.

In addition, the experimental data of Group II were used to compute the dimensionless parameters $\frac{l}{R_{b}}$ and $\frac{u \cdot t}{R_{b}}$ for each sample (Table 2). The results showed that the best relationship was an exponential equation (Fig. 5) as follows:

$$
\frac{l}{R_{b}}=b\left(\frac{u \cdot t}{R_{b}}\right)^{a}
$$

where, $a=1.212$ and 1.214 for sediment Samples A and $B$, respectively. It should be noted that the difference of coefficient $b$ for two sediment sizes does not exceed $2 \%$ for the same flow condition. This is consistent with the findings of Soni [5] during their study on aggradation due to overloading sediment in the channel.

This means that $b$ value depends on the quantity of sediment transported in the stream. Eq. (7) was applied on the experimental data for Group I experiments that had the same water discharge to check the variation of $b$ with changing the quantity of sediment (Table 3). The results showed that $b$ value increases linearly with the quantity of sediment (Fig. 6).

The shape factor of sediment distribution $A_{i}$ was computed for the experiments in Group II to see the effect of flow velocity of transient bed profile (Table 3). The results showed that the logarithmic relation was the best to represent this relationship as follows (Fig. 7):

$$
A_{i}=c \cdot \ln \frac{u \cdot t}{R_{b}}+d
$$

where, $c$ and $d$ are constants $(-0.222,2.88$ for sediment Sample A and -0.223, 2.89 for Sample B) with relation correlation $(0.955,0.96)$ for both, respectively. These results are for Group II experimental constant conditions for the water discharge and sediment quantity.

To determine the transient bed profile or deposited depth along the aggradation each, the values of $\frac{Z}{Z_{i}}$ and $\frac{u \cdot t}{R_{b}}$ for different ratios of $\frac{x}{l}=(0.0,0.25,0.5$ and 0.75$)$ for experiments Group II were computed (Fig. 8). The transient bed profiles (depth of sediment along the bed) for experiments in Group I were computed using Eqs. (4), (7) and (8) with the charts of Fig. 8 as follows:

\begin{tabular}{|c|c|c|c|c|c|c|c|c|c|c|c|}
\hline \multirow{2}{*}{\multicolumn{2}{|c|}{$\begin{array}{l}Q=23.3 \times 10^{-3}\left(\mathrm{~m}^{3} / \mathrm{s}\right) \\
G_{e}=1.97 \times 10^{-5}\left(\mathrm{~m}^{3} / \mathrm{s}\right)\end{array}$}} & \multicolumn{10}{|c|}{ Initial average water flow velocity $u(\mathrm{~m} / \mathrm{s})$} \\
\hline & & 0.33 & 0.35 & 0.48 & 0.564 & 0.625 & 0.685 & 0.72 & 0.74 & 0.87 & 0.96 \\
\hline \multicolumn{2}{|c|}{ Initial flow depth (m) } & 0.086 & 0.082 & 0.06 & 0.051 & 0.046 & 0.042 & 0.04 & 0.039 & 0.033 & 0.03 \\
\hline \multicolumn{2}{|c|}{$R_{b}(\mathrm{~m})$} & 0.071 & 0.0682 & 0.052 & 0.0453 & 0.0413 & 0.038 & 0.0364 & 0.0355 & 0.0305 & 0.0279 \\
\hline \multicolumn{2}{|l|}{$\frac{u \cdot t}{R_{b}}$} & 16,756 & 18,475 & 33,103 & 44,821 & 54,479 & 64,895 & 71,209 & 75,042 & 102,688 & 123,871 \\
\hline \multirow{6}{*}{ 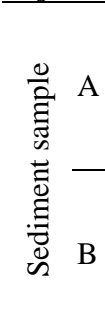 } & $l(\mathrm{~m})$ & 2.55 & 2.7 & 4.0 & 5.76 & 5.86 & 6.95 & 8.12 & 8.48 & 9.65 & 10.6 \\
\hline & $\frac{l}{R_{b}}$ & 35.97 & 39.59 & 76.63 & 127.15 & 141.9 & 182.89 & 223.1 & 238.87 & 316.4 & 380 \\
\hline & $A_{i}$ & 0.688 & 0.682 & 0.613 & 0.484 & 0.49 & 0.47 & 0.376 & 0.352 & 0.299 & 0.26 \\
\hline & $l(\mathrm{~m})$ & 2.5 & 2.67 & 3.85 & 5.6 & 5.7 & 6.86 & 8.0 & 8.37 & 9.4 & 10.45 \\
\hline & $\frac{l}{R_{b}}$ & 35.26 & 39.15 & 73.75 & 123.62 & 138.57 & 180.5 & 219.78 & 235.77 & 308.2 & 374.55 \\
\hline & $A_{i}$ & 0.686 & 0.687 & 0.62 & 0.505 & 0.52 & 0.44 & 0.386 & 0.369 & 0.31 & 0.25 \\
\hline
\end{tabular}

Table 2 Relevant calculations for $\frac{l}{R_{b}}, \frac{u \cdot t}{R_{b}}$ and $A_{i}$ of the aggradation for the experiments Group II. 


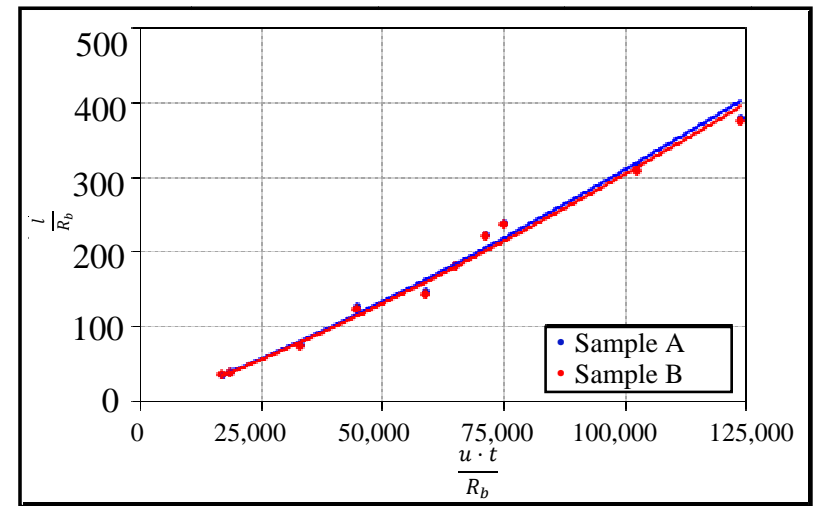

Fig. 5 Relationship between $\frac{l}{R_{b}}$ and $\frac{u \cdot t}{R_{b}}$ for experiments Group II.

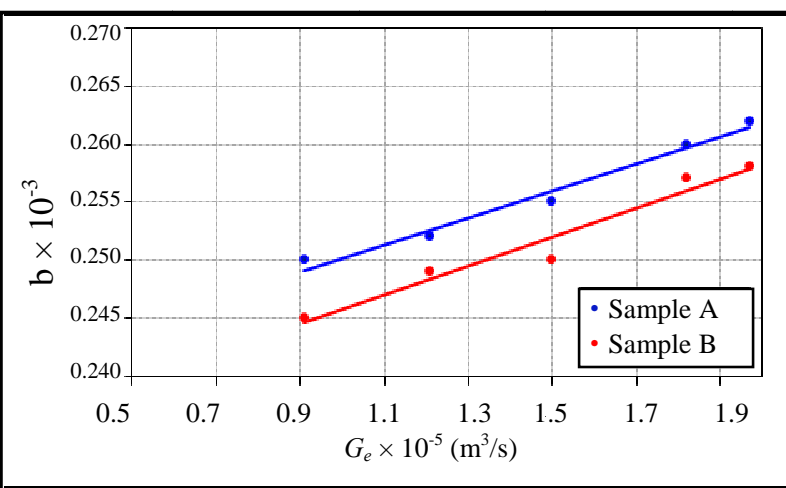

Fig. 6 Variation of $b$ with amount of sediment $G_{e}$ for Group I of experiments $\left(Q=23.3 \times 10^{-3} \mathrm{~m}^{3} / \mathrm{s}\right)$.

Eq. (4) was used to compute the maximum depth of sediment deposited depending on the shape factor that was computed using Eq. (8). Then, Eq. (7) was used to determine the length of transient bed profile and finally, the sediment deposited depth at different distances from the measurement section was estimated using the charts in Fig. 8. The results from empirical method were compared with data measured. The comparison showed that the percentage error ranged between -19\% to $31 \%$ and $-21 \%$ to $26 \%$ for the length and maximum depth of aggradation, respectively. In addition, the numerical method that was proposed [2] for the aggradation upstream where the reservoir was used to determine the transient bed profile. This analytical method depends on the continuity equation of sediment transport and water surface profile equation. The results were compared with the experimental measurements to test the reliability of this method. The results showed that the percentage error for maximum depth of aggradation ranged between $-17 \%$ to $61.5 \%$. It should be mentioned, however, that the length of the aggradation was assumed to be equal to that measured in the experiments conducted for $60 \mathrm{~min}$ of the time test.

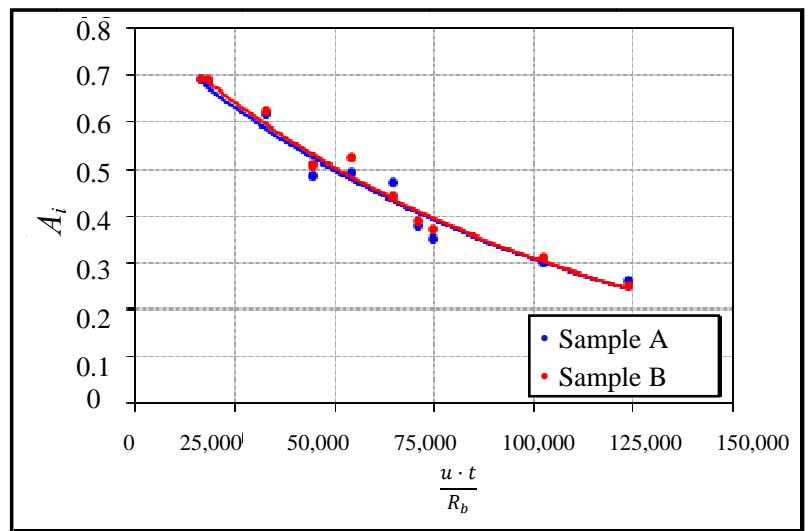

Fig. 7 Relationship between $A_{i}$ and $\frac{u \cdot t}{R_{b}}$ for experiments Group II.

Table 3 Relevant calculations for constant $b$ of the aggradation experiments Group I $\left(Q=23.3 \times 10^{-3} \mathrm{~m}^{3} / \mathrm{s}\right)$.

\begin{tabular}{|c|c|c|c|c|c|c|}
\hline$Q=23.3 \times 10^{-3}\left(\mathrm{~m}^{3} / \mathrm{s}\right)$ & & & $413(\mathrm{~m})$ & & $\frac{u \cdot t}{R_{b}}=$ & \\
\hline \multirow[b]{2}{*}{$G_{e} \times 10^{-5}\left(\mathrm{~m}^{3} / \mathrm{s}\right)$} & \multicolumn{3}{|c|}{ Sample A } & \multicolumn{3}{|c|}{ Sample B } \\
\hline & $l(\mathrm{~m})$ & $\frac{l}{R_{b}}$ & $b \times 10^{3}$ & $l(\mathrm{~m})$ & $\frac{l}{R_{b}}$ & $b \times 10^{3}$ \\
\hline 0.91 & 5.7 & 138.0 & 0.25 & 5.66 & 137.0 & 0.245 \\
\hline 1.21 & 5.76 & 139.5 & 0.252 & 5.7 & 138.0 & 0.249 \\
\hline 1.5 & 5.86 & 141.9 & 0.255 & 5.76 & 139.5 & 0.25 \\
\hline 1.82 & 5.95 & 144.1 & 0.26 & 5.95 & 144.1 & 0.257 \\
\hline 1.97 & 6 & 145.3 & 0.263 & 5.96 & 144.3 & 0.258 \\
\hline
\end{tabular}



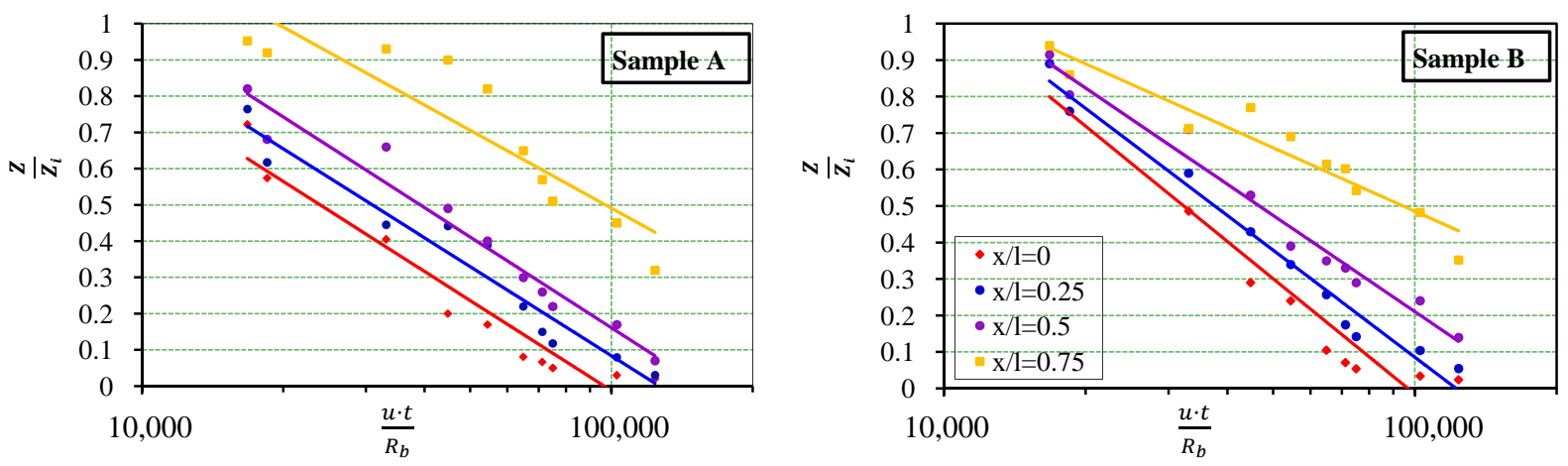

Fig. 8 Variation of $\frac{Z}{Z_{i}}$ with $\frac{u \cdot t}{R_{b}}$ for different ratios of $\frac{x}{l}$ of sediment samples for experiments Group II.

\section{Conclusions}

In this research, experimental investigation of the process of aggradation phenomenon upstream reservoir had been conducted. A number of influencing factors such as sediment transport rate, particle size of sediment and varied flow velocity were studied. The results showed that there was a strong linear direct relationship between aggradation elements (length and maximum depth of sediment deposited) with the rate of sedimentation. The results also showed that the length and maximum depth of aggradation was reduced by no more than $5.4 \%$ and $31 \%$, respectively, when the particle size of sediment was increased by $78 \%$. This implies that the variation of sediment particle size has little effect on aggradation length when compared with deposited depth. For the same conditions of water discharge and sediment quantity, the length of aggradation increased linearly with increasing flow velocity or decreasing water stage in the reservoir but the aggradation depth decreases. Furthermore, part of the experimental data was used to develop an empirical approach using dimensional analysis parameters. This procedure had also been tested with another set of data. The empirical approach indicated that the percentage error with measured data ranged between -19\% to 31\% for length of aggradation and $-21 \%$ to $26 \%$ for maximum depth of aggradation.

\section{Acknowledgments}

The authors would like to express their thanks and gratitude to Mosul University, Iraq for supporting this research in particular the staff of the Hydraulic Laboratory, Mosul University for their help and support during the experiments.

\section{References}

[1] B.D. Simons, F. Senturk, Sediment Transport Technology, Water Resources Publication, Fort Collins, Colorado, USA, 1977.

[2] R.J. Grade, K.G.R. Raju, Mechanics of Sediment Transportation and Alluvial Stream Problems, 2nd ed., Wiley Eastern Limited, New Delhi, 1985.

[3] S.K. Jain, V.P. Singh, Water Resources Systems Planning And Management, Elsevier Science B.V., Amsterdam, 2003.

[4] J.P. Soni, R.J. Garde, K.G.R. Raju, Aggradation in streams due to overloading, Journal of the Hydraulics Division: Proceedings of ASCE (American Society of Civil Engineering) 106 (1980) 117-132.

[5] J.P. Soni, Laboratory study of the aggradation in alluvial channels, Journal of Hydrology 49 (1981) 87-106.

[6] T.E. Lisle, J.E. Pizzuto, H. Ikeda, F. Iseya, Y. Kodama, Evolution of a sediment wave in an experimental channel, Water Resources Research 33 (1997) 1971-1981.

[7] G. Tayfur, V.P. Singh, Kinematic wave model of bed profiles in alluvial channels, Water Resources Research 42 (6) (2006) W06414.

[8] G. Tayfur, V. Singh, Simulating transient sediment waves in aggraded alluvial channels by double-decomposition method, Journal of Hydrologic Engineering 16 (4) (2011) 362-370.

[9] S.C. Jain, River bed aggradation due to overloading, Journal of the Hydraulics Division: Proceedings of ASCE 107 (1981) 120-124.

[10] J.P. Soni, An error function solution of sediment transport in aggradation channels, Journal of Hydrology 49 (1981) 107-119. 
[11] J.P. Soni, Unsteady sediment transport law and prediction of aggradation parameters, Water Resources Research 17 (1) (1981) 33-40.

[12] J.S. Ribberink, T.S. Vandersand, Aggradation in rivers due to overloading analytical approaches, Journal of Hydraulic Research 23 (3) (1985) 273-283.

[13] G. Parker, C. Paola, E. Carlos, Transfer function for deposition of poorly sorted gravel in response to stream bed aggradation, Journal of Hydraulic Research 34 (1) (1996) 35-53.

[14] W. Wu, D.A. Vieira, S.S.Y. Wang, One-dimensional numerical model for nonuniform sediment transport under unsteady flows in channel networks, Journal of Hydrologic Engineering 130 (9) (2004) 914-923.

[15] J. Fan, G.L. Morris, Reservoir sedimentation, Part I: Delta and density current deposits, Journal of Hydrologic Engineering 118 (3) (1992) 354-369.

[16] G.L. Morris, J. Fan, Reservoir Sedimentation Handbook, Design and Management of Dams, Reservoirs and Watersheds for Sustainable Use, McGraw-Hill Book Co., New York,1998.

[17] J.S. Lai, H.W. Shen, Flushing sediment through reservoirs, Journal of Hydraulic Research 34 (2) (1996) 237-255.

[18] H.W. Shen, Flushing sediment through reservoirs, Journal of Hydraulic Research 37 (6) (1999) 743-757.

[19] E.I. Issa, N. Al-Ansari, S. Knutsson, M. Khaleel, Sediment delivered in the upper part of Mosul reservoir using physical model, Journal of Civil Engineering and Architecture 6 (11) (2012) 1544-1550. 